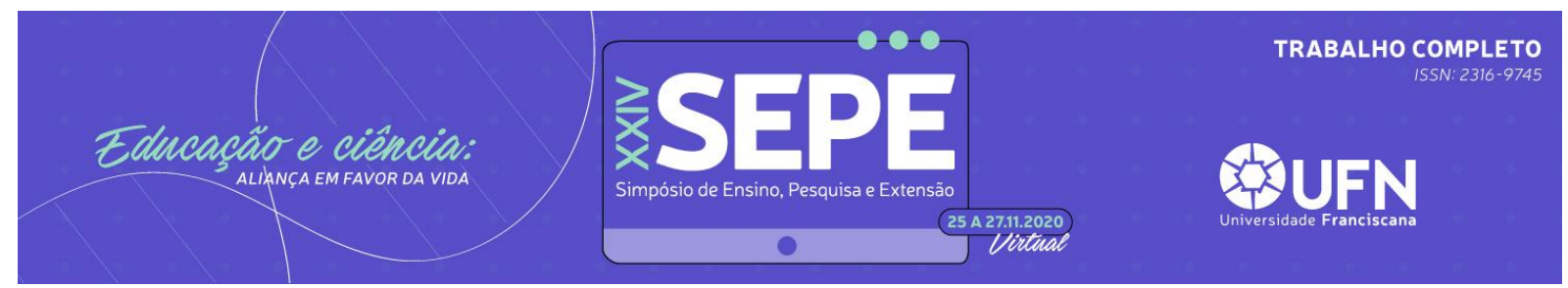

http://doi.org/10.48195/sepe2021-026

\title{
PULPOTOMIA EM DENTES DECÍDUOS UTILIZANDO FORMOCRESOL
}

\section{Angélica Kerber ${ }^{1}$, Victória Paniz ${ }^{1}$, Cristiane Medianeira Savian ${ }^{2}$, Cândida Bonadiman Jung ${ }^{3}$, Bianca Zimmermann Santos ${ }^{4}$, Letícia Westphalen Bento ${ }^{4}$, Simone Pippi Antoniazzi ${ }^{4}$, Maurício Barbieri Mezomo ${ }^{5}$}

\footnotetext{
Acadêmico do Curso de Odontologia - Universidade Franciscana - UFN

${ }^{2}$ Mestre em Saúde Materno Infantil - Universidade Franciscana - UFN

${ }^{3}$ Mestranda em Saúde Materno Infantil - Universidade Franciscana - UFN

${ }^{4}$ Professora do Curso de Odontologia - Universidade Franciscana - UFN

${ }^{5}$ Orientador. Professor do Curso de Odontologia - Universidade Franciscana - UFN
}

\section{RESUMO}

No presente trabalho foi verificada na literatura qual a eficácia da utilização do medicamento formocresol em tratamento de pulpotomia de dentes decíduos, visando esclarecer quais as controvérsias para sua utilização. As buscas foram realizadas nas bases de dados MEDLINE/PubMed utilizando-se os seguintes descritores MeSH: "pulpotomy", "deciduous tooth" "formocresol", combinados pelo operador booleano $A N D$. Não foi realizada a delimitação temporal. Foram incluídos somente artigos que contemplassem a temática proposta. As buscas foram realizadas no mês de julho de 2021. Embora a literatura apresente resultados clínicos satisfatórios em pulpotomias de dentes decíduos com formocresol, ainda existem controvérsias entre profissionais no mundo inteiro acerca de seu uso. Sendo assim, torna-se importante a busca por outros materiais que apresentem potencial biológico aos tecidos pulpares, demonstrando sucesso clínico e radiográfico semelhantes ao formocresol.

Palavras-chave: Dente decíduo; Formocresol; Pulpotomia.

Eixo Temático: Ciências da Saúde.

\section{INTRODUÇÃO}

A manutenção do elemento dental decíduo até que ocorra sua esfoliação fisiológica é um dos principais objetivos da clínica odontopediátrica, já que a primeira dentição é responsável pela manutenção de espaço adequado para os dentes permanentes irromperem, servindo de guia para o posicionamento dos mesmos (RIBEIRO et al., 2011). O exame radiográfico é importante no complemento ao diagnóstico em odontopediatria. Por meio dele, é possível observar e interpretar 


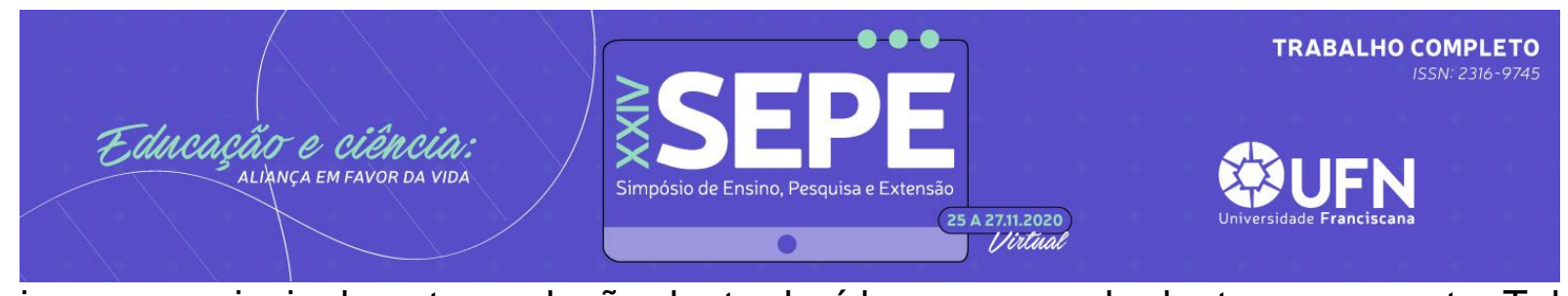

imagens, principalmente a relação dente decíduo e germe do dente permanente. Tal fato assume um papel de grande importância para o especialista, pois possibilita a tomada de decisões seguras no estabelecimento de um adequado plano de tratamento (CARVALHO et al., 2010).

A presença de lesões de cárie e traumatismos dentários, os quais acometem um número significativo de crianças na fase de dentição decídua, são as principais causas de perda do elemento dental precocemente (NETO et al., 2013). As terapias na dentição decídua incluem uma variedade de procedimentos operatórios que dependem de alguns fatores de diagnóstico como o grau de comprometimento pulpar e a relação entre o dente decíduo e seu sucessor permanente (PINHEIRO et al., 2013). Nesse sentido, justificam-se pesquisas de técnicas e materiais que colaborem para a manutenção de dentes decíduos até a época da sua esfoliação fisiológica, mesmo nos casos que houver envolvimento pulpar.

\section{METODOLOGIA}

O estudo trata de uma revisão de literatura e para o desenvolvimento desta, foi realizada uma busca de artigos referentes ao tema estudado, na base de dados MEDLINE/PubMed. A pesquisa foi realizada no mês de julho de 2021. Foram utilizados os seguintes descritores do MeSH: "pulpotomy", "deciduous tooth" "formocresol", combinados pelo operador booleano AND. A delimitação temporal definida foi 2003 a 2021.

Foi realizada a leitura dos títulos e resumos de todos os artigos encontrados, para adequada inclusão dos trabalhos relacionados ao tema. Como critério de inclusão foi considerado: artigos que contemplassem a temática proposta, publicados em português, inglês e espanhol. O critério de exclusão estabelecido foi artigos que não estivessem com o texto completo disponível.

\section{RESULTADOS E DISCUSSÃO}

A pulpotomia em dentes decíduos é uma técnica conservadora de terapia pulpar muito usada em Odontopediatria, sendo importante para evitar a perda prematura desses dentes, quer seja por lesões extensas de cárie ou traumatismo 


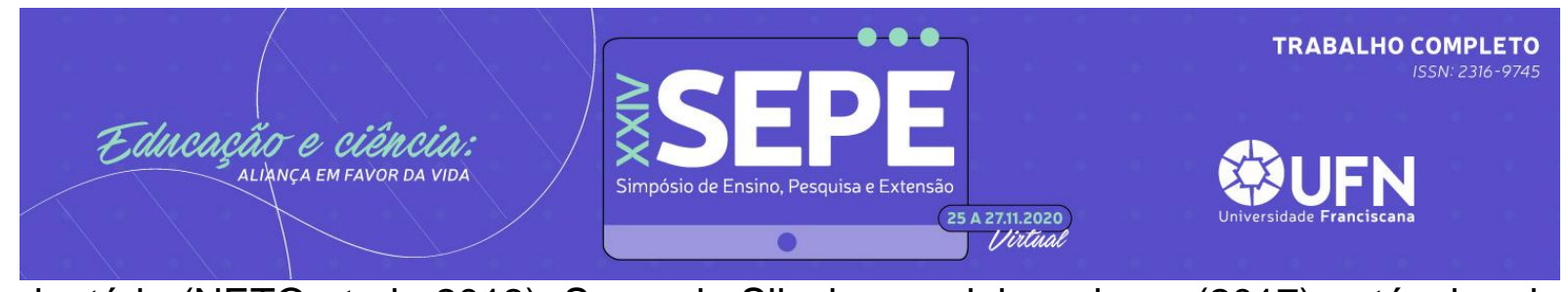

dentário (NETO et al., 2013). Segundo Silveira e colaboradores (2017), a técnica de pulpotomia está indicada quando há exposição pulpar durante a remoção de tecido cariado, e caso a polpa esteja com características saudáveis, ou seja, sem sintomatologia dolorosa ou com pulpite reversível, assim como após exposição por trauma dentário.

Pesquisas atuais da biologia celular e molecular, bem como conhecimento acerca do desenvolvimento dentário, contribuíram para o surgimento de materiais mais biocompatíveis, indicados para pulpotomia de dentes decíduos (SAKAl et al., 2009). Essas medicações auxiliam na melhor técnica dos materiais capeadores pulpares no auxílio do processo de reparo da polpa dental. Essa técnica consiste na remoção da polpa coronária, seguida de aplicação de medicamentos sobre os cotos radiculares a fim de estimular a sua fixação ou reparo (ANSARI; RANJPOUR, 2010).

O formocresol trata-se de um medicamento, o qual é um agente fixador, que tem capacidade mumificante. Provoca uma desnaturalização das proteínas da polpa radicular mais próxima à câmara pulpar e difunde até à polpa mais apical, fixando os tecidos em maior ou menor medida (SILVA; LEACHE, 2010). O formocresol é constituído de formaldeído a 19\%, cresol a 35\%, glicerina a 15\% e água destilada (FERNANDES et al., 2003). Segundo Silva e Leache (2010), o cresol é cáustico e o formaldeído é um produto que provoca infiltrações de células inflamatórias nos tecidos próximos aos dentes desenvolvidos. Segundo Fernandes e colaboradores (2003), o tratamento com formocresol não pode ser considerado biológico, pois após sua utilização não ocorre reparação pulpar. O sucesso deste medicamento está mais relacionado à ação bactericida e as propriedades de fixação do que sua capacidade de promover cicatrização.

\section{CONCLUSÃO}

Embora a literatura apresente resultados clínicos satisfatórios em pulpotomias de dentes decíduos com formocresol, ainda existem controvérsias entre profissionais no mundo inteiro acerca de seu uso. Sendo assim, torna-se importante a busca por 


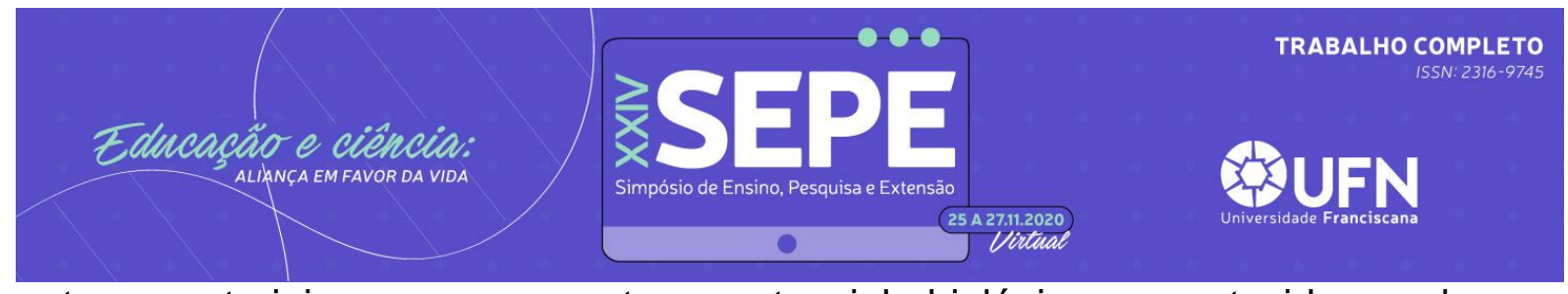

outros materiais que apresentem potencial biológico aos tecidos pulpares, demonstrando sucesso clínico e radiográfico semelhantes ao formocresol.

\section{REFERÊNCIAS}

ANSARI, G.; RANJPOUR, M. Mineral trioxide aggregate and formocresol pulpotomy of primary teeth: a 2-year follow-up. Int Endod J, v. 43, p. 413-418, 2010.

CARVALHO, P. L. D.; LOPES, A. M. D. S.; SILVA, C. M. D.; ASSIS, A. C. D. S.; MEDEIROS, J. M. F. D. Utilização de protocolo radiográfico na clínica de Odontopediatria. Rev Bras Odontol, v. 67, n. 2, p279-282, 2010

FERNANDES, D. S. C.; JUNIOR, I. M. F.; KRAMER, P. F.; ULIAN, J. Pulpotomias com Formocresol em Dentes Decíduos, RGO, v. 51, n. 3, p. 154-161, 2003.

NETO, N. L.; FERNANDES, A. P.; MARQUES, N. C. T.; SAKAI, V. T.; MORETTI, A. B. S.; MACHADO, M. A. A. M.; ABDO, R. C. C.; OLIVEIRA, T. M. Terapia pulpar em dentes decíduos: possibilidades terapêuticas baseadas em evidências. Rev Odontol UNESP, v. 41, n. 2, p. 130-137, 2013.

PINHEIRO, H. H. C.; ASSUNÇÃO, L. R. S.; TORRES, D. K. B.; MIYAHARA, L. A. N.; ARANTES, D. C. Pesq Bras Odontoped Clin Integr, João Pessoa, v. 13, n. 4, p. 351-60, 2013.

RIBEIRO, M. N.; RAMOS, M, E. P. L.; PEIXOTO, K. D. S. Saúde bucal em crianças na idade escolar em Nova Xavantina-MT. Revista eletrônica Univar, v. 6, p. 12-6, 2011.

SAKAI, V. T.; MORETTI A. B.; OLIVEIRA T. M.; FORNETTI, A. P.; SANTOS C. F.; MACHADO, M. Pulpotomy of human primary molars with MTA and Portland cement: a randomised controlled trial. Br Dent J, v. 207, n. 3, 2009

SILVA, C. C.; LEACHE, E. B. Utilização do Agregado Trióxido Mineral (MTA) em pulpotomias de molares temporários. Dentistry Clinica, 2010. 


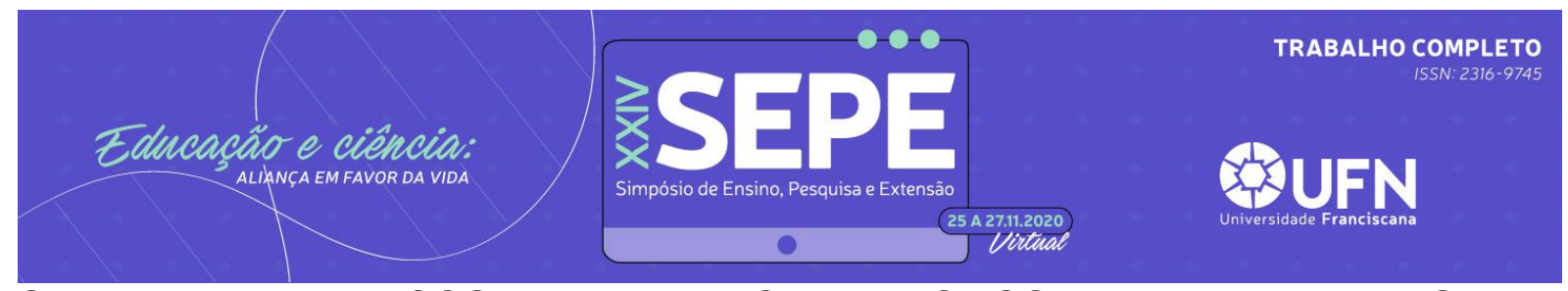

SILVEIRA, M. P. M.; COSTA, R. M.; AMORIM, K. S.; SOUZA, L. M. A.; TAKESHITA, E. M. Avaliação da eficácia anestésica do Morpheus através da técnica intrasseptal CaZOE na pulpotomia de dentes decíduos: estudo-piloto. Rev Odontol UNESP, v. 46, n. 3, p. 147-152, 2017. 